\title{
Current understanding of Th2 cell differentiation and function
}

\author{
Zhenhu Li ${ }^{1}$, Yuan Zhang ${ }^{1}$, Bing Sun ${ }^{1,2} \bowtie$ \\ ${ }^{1}$ Laboratory of Molecular Cell Biology, Institute of Biochemistry and Cell Biology, Shanghai Institutes for Biological Sciences, \\ Chinese Academy of Sciences, Shanghai 200031, China \\ 2 Molecular Virus Unit, Key Laboratory of Molecular Virology \& Immunology, Institut Pasteur of Shanghai, Chinese Academy of \\ Sciences, Shanghai 200031, China \\ $\bowtie$ Correspondence: bsun@sibs.ac.cn
}

Received July 24, 2011 Accepted August 9, 2011

\begin{abstract}
Helper T cell (Th) has been identified as a critical immune cell for regulating immune response since 1980s. The type 2 helper T cell (Th2), characterized by the production of interleukin-4 (IL-4), IL-5 and IL-13, plays a critical role in immune response against helminths invading cutaneous or mucosal sites. It also has a functional role in the pathophysiology of allergic diseases such as asthma and allergic diarrhea. Currently, most studies have shed light on Th2 cell function and behavior in specific diseases, such as asthma and helminthes inflammation, but not on Th2 cell itself and its differentiation. Based on different cytokines and specific behavior in recent research, Th2 cell is also regarded as new subtypes of $\mathrm{T}$ cell, such as IL-9 secreting T cell (Th9) and CXCR5 ${ }^{+} \mathrm{T}$ follicular helper cells. Here, we will discuss the latest view of Th2 cell towards their function and the involvement of Th2 cell in diseases.
\end{abstract}

KEYWORDS type 2 helper T cell (Th2), asthma, IL-9 secreting T cell (Th9), T follicular helper cell

\section{INTRODUCTION}

The immune system is the defense system to protect body from the invasion of foreign challenges, such as bacteria, parasites, fungi as well as to control inner abnormal affairs, like cancer or autoimmune diseases. After billions of years of evolution, the immune system has developed precise, effective and complicated mechanisms to combat those foreign enemies. The immune system is divided into innate immune system and adaptive one; the former can react quickly to a wide range of frequently encountered antigens, while the latter can recognize subtle differences between antigens, give more specific reactions, and keep memory of the antigens it has encountered. $\mathrm{CD} 4^{+} \mathrm{T}$ cells play a central role in adaptive immune system, by helping the activation and maintenance of $\mathrm{CD}^{+} \mathrm{T}$ cells and macrophages, mediating $\mathrm{B}$ cells in antibody production and class switching, regulating immune responses when necessary, and most importantly, recognizing a huge range of pathogenic antigens, and taking corresponding actions against them.

\section{Th2 DIFFERENTIATION AND CELL SIGNALING}

After the engagement of the $\mathrm{T}$ cell receptor (TCR) with peptide-MHC-II complex (major histocompatibility complex class II) processed by the antigen presenting cell (APC), which triggers clonal expansion, $\mathrm{CD}^{+}$helper $\mathrm{T}$ cells rapidly undergo programmed differentiation (Abbas et al., 1996; Ho and Glimcher, 2002). This differentiation process results in highly polarized immune responses, such as $\mathrm{T}$ cell related cytokines and chemokines secretion, or helping B cells to switch antibody isotypes.

Naïve helper T cell can differentiate into at least four major subsets, including Th1, Th2, regulatory T cell (Treg) and Th17 (Mosmann et al., 1986; Weaver and Hatton, 2009). Th1 cells, which produce large quantities of interferon-y (IFN- $\gamma$ ) and interleukin-12 (IL-12), are involved in enhancing clearance of certain intracellular pathogens. The development of Th2 cells, which evolve to enhance the clearance of parasites, is coupled to IL-4. Subsequently, the identification of the interleukin 17 (IL-17)-producing T helper (Th17) subset as well as transforming growth factor (TGF- $\beta$ )-induced regulatory T cells (iTreg cells) has added to the CD4 ${ }^{+}$effector T cell program (Fig.1).

By the 1990s, classic studies on helper T cell differentiation 


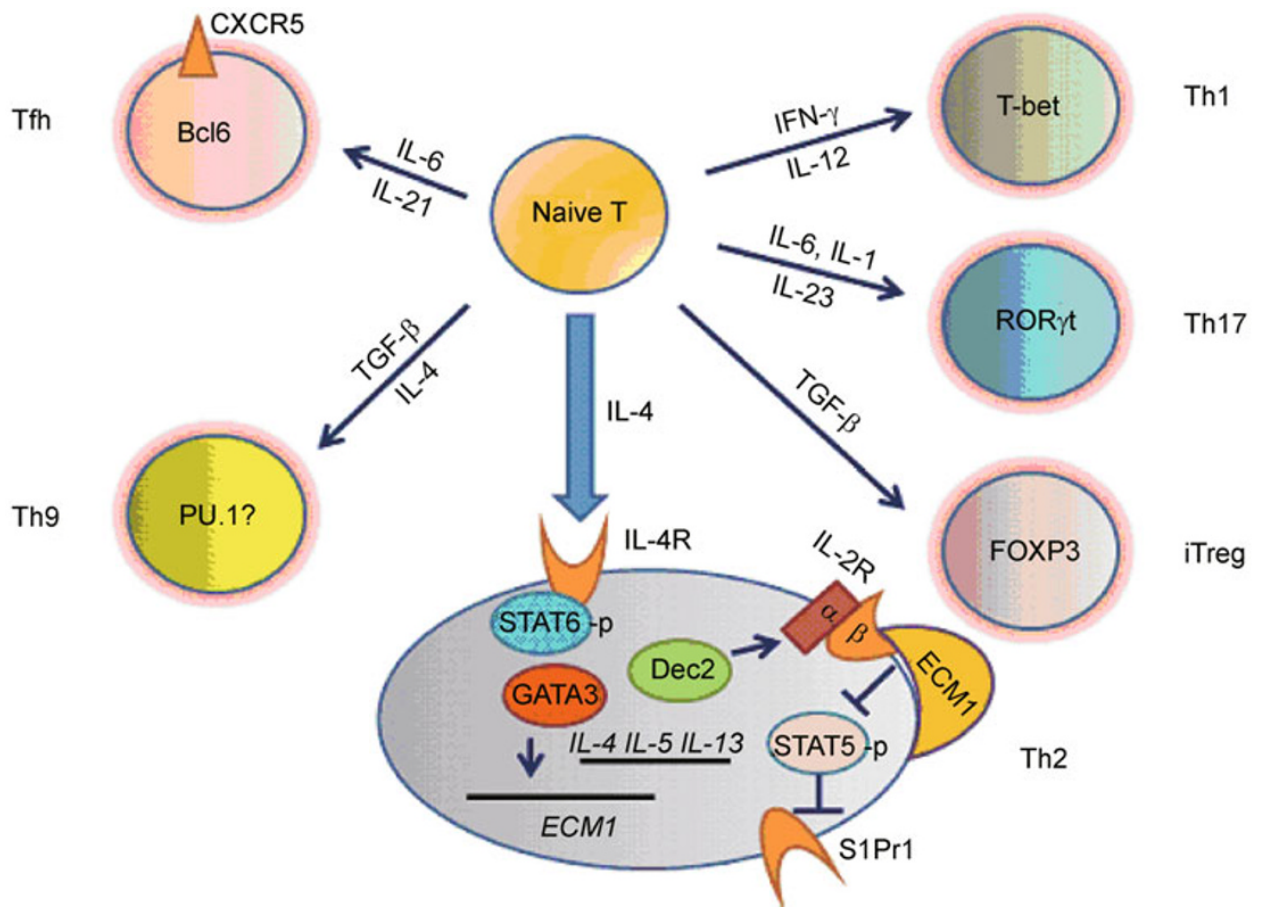

Figure 1. $\mathrm{CD}^{+} \mathrm{T}$ cell subsets and Th2 signaling. Naïve T cells can develop into different subsets when facing different cytokine milieus. In Th2 cells, GATA3 remodels IL-4 locus into a more accessible condition. Dec2 caused IL-2Ra up-regulation and can cooperate with GATA3 to enhance Th2 differentiation. GATA3 directly activates ECM1 expression, and ECM1 blocks STAT5 phosphorylation by interaction with IL-2Rß, by which the negative signal of S1Pr1 re-expression is released, and mature Th2 cells can egress lymph node under the calling of high level of S1P.

had been fully explored. The process by which an uncommitted helper T cell develops into a mature Th1 or Th2 cell is a useful model of developmentally regulated gene expression, T-bet for Th1 cell and GATA3 for Th2 cell (Ouyang et al., 2000; Szabo et al., 2000; Szabo et al., 2002). There is good evidence to indicate that this differentiation process is highly plastic. Many factors influence the decision to become a Th1 or Th2 cell. The cytokines IL-12 and IL-4, acting through signal transducer and activator of transcription 4 (STAT4) and STAT6, respectively, are key determinants of the outcome (Kaplan et al., 1996; Mullen et al., 2001; O'Shea et al., 2011). It also has been reported that antigen dose, co-stimulators, genetic modifiers and other non-cytokine factors have crucial roles in determining the dominance of helper T cell response (Ho et al., 1996; Schweitzer et al., 1997; Lee et al., 2001; Rothoeft et al., 2003). However, how each signaling influences the differentiation process of helper T cells is still controversial.

In the past 20 years, several lines of evidence have indicated that chromatin structure has an integral role in helper T cell differentiation (Murphy and Reiner, 2002). The induction of competence for effector-cytokine gene expression seems to be involved in derepression of silent chromatin contexts (Agarwal and Rao, 1998; Bird et al., 1998; Agarwal et al., 2000). For Th2 epigenetic research, //4 locus is actively repressed in naïve $C D 4^{+} \mathrm{T}$ cells by molecules that link methylated DNA to repressive chromatin. Together, methylCpG-binding domain protein 2 (MBD2) and nucleosome remodeling and histone deacetylase (NURD) form the MeCP1 complex (Hutchins et al., 2002). The sites of action of this repression probably overlap with crucial cis-acting elements in the locus, such as the IL-4-IL-13 intergenic region (CNS1), the second intron of IL-4, and the 3' enhancer (CNS2) (Mohrs et al., 2001). Activation of the locus occurs in a stepwise fashion. First, GATA3 mediates displacement of MBD2, leading to chromatin changes such as histone acetylation, an effect that is concurrent with the induction of IL-4 transcription. Later, the acquisition of additional epigenetic changes, such as stable $\mathrm{CpG}$ demethylation, occurs along the cytokine gene. A recent study has reported that HS2 is the target of GATA-3 in regulating chromosomal modification of the //4 locus and is independent of the $/ / 5$ and I/13 loci (Tanaka et al., 2011).

One of the important transcript factors of Th2 development is Dec2, a basic helix-loop-helix (bHLH). We found Dec2 is selectively expressed in Th2 cells, and overexpressing Dec2 by retrovirus-infection or transgenic manipulation could promote Th2 development in Th2 cytokine milieu, while Dec2 deletion leads to less Th2 cytokine expression, such as IL-4, IL-5 and IL-13, in both in vitro and in vivo conditions. In 
further work, Dec2 is found directly bind to the Junb CNS and the Gata3 promoter to activate their transcription, and can promote CD25 level in Th2, which shows Dec2 may help Th2 development in both differentiation and proliferation aspects (Liu et al., 2009; Yang et al., 2009) (Fig. 1).

\section{Th2 CELL AND ALLERGY ASTHMA}

Asthma is defined as a chronic inflammatory lung disease that is characterized by airway hyperreactivity and mucus hypersecretion that results in intermittent airway obstruction (Busse and Lemanske, 2001). It has been known for a long time that atopic individuals, including those with atopic dermatitis, allergic rhinitis and asthma, have an inherited predisposition to become sensitized to commonly encountered environmental allergens and to develop high levels of immunoglobulin $E$ antibodies. However, the reason for mounting these IgE responses was not well understood until the discovery of Th1 and Th2 subtypes of $\mathrm{CD} 4^{+} \mathrm{T}$ helper cells (Kim et al., 1985; Mosmann et al., 1986). The high levels of Th2-type cytokines that are found at sites of allergic inflammation are consistent with a Th2-cell-based etiology of atopic disease (Robinson et al., 1992; Walker et al., 1992; Robinson et al., 1993). Furthermore, studies using mouse models of asthma have shown that allergic airway inflammation is dependent on $\mathrm{CD}^{+} \mathrm{T}$ cells and, more specifically, is seen when T-cell receptor transgenic Th2, but not Th1, cells are adoptively transferred to mice (Brusselle et al., 1994; Cohn et al., 1998). Finally, the absolute requirement for Th2 cells in directing allergic airway inflammation has been shown by the use of IL-4 deficient mice. In these studies, defective priming of Th2 cells in the absence of IL-4 resulted in a failure to generate allergic inflammatory responses after subsequent airway challenge (Kips et al., 1995; Corry et al., 1996). Moreover, other Th2 related cytokines have also been proved to have their individual roles in airway inflammation and allergic asthma (Herrick and Bottomly, 2003).

Recently, T cell trafficking is known as one of key steps for asthma induction (Medoff et al., 2008). This progress contains amplified Tcell migrating into allergic lung and memory T cells back to lymph nodes (LN). After exposure to allergen, the number of $T$ cells in the airways increases dramatically, amplifying allergic inflammation (Lommatzsch et al., 2006; Thomas et al., 2007). Experiments in animal models have demonstrated that, following allergen challenge, antigen specific $T$ cells in the airways do not proliferate but are recruited into the lung from regional lymph nodes, leading to the increase in T cells in the airways (Harris et al., 2002). This increase is dependent on both $\mathrm{T}$ cell proliferation and $\mathrm{T}$ cell egress into inflammatory sites. After 2000 , many T cell migration control receptors have been studied as critical targets for regulating $\mathrm{T}$ cell migration, such as $\mathrm{S}_{1} \mathrm{P}_{1}$. Recent studies indicate that the emigration of T cells from thymus and secondary lymphoid organs is also regulated by S1P receptors (Schwab and Cyster, 2007; Rivera et al., 2008). S1P is a natural lysophospholipid found at micromolar concentrations in the plasma. S1P receptors, including $\mathrm{S}_{1} \mathrm{P}_{1}$ and $\mathrm{S}_{1} \mathrm{P}_{4}$, which are highly expressed on $\mathrm{T}$ cells, consist of five known $\mathrm{G}$ protein-coupled receptors (Rivera et al., 2008). An immunosuppressive agent, FTY720, acts as an agonist for S1P receptors. FTY720 binds to S1P1, S1P3, S1P4 and S1P5 and inhibits lymphocyte emigration from lymphoid organs (Brinkmann et al., 2002; Mandala et al., 2002). S1P $\mathrm{P}_{1}$-deficient $T$ cells in mice fail to exit into blood (Harris et al., 2002). Moreover, for Th2 cell emigration, ECM1 was identified as an important regulating point, which functions through $\mathrm{S}_{1} \mathrm{P}_{1}$ re-expression at the late stage $(\mathrm{Li}$ et al., 2011) (Fig.1).

\section{Th2 AND Th9: TWINS FROM ONE FAMILY}

Although Th2 cell was proven to have a lot of functions for immune response as a genetically stable subset in past studies, some not so classical "brother subsets" were also identified in recent years, such as Th9 cell. IL-9 was first linked to Th2 cells, along with IL-4, IL-5 and IL-13, and constitutes the Th2 cytokine profile. It is reported that levels of IL-9 expression were high in the Th2-prone BALB/c mouse strain but low in the Th1-prone C57BL/6 mouse strain during infection with Leishmania major (Gessner et al., 1993). The same study showed that $T$ cells were the main producers of IL-9 in vivo and the levels of IL-9 expression correlated with the expansion of Th2 cell populations. Furthermore, blockade of IL-4, which is a crucial mediator of Th2 cell differentiation, could suppress IL-9 production. Owing to recent characterization of Th9 cells [which express IL-9 but not the key signature cytokines of other helper T cell subsets, such as IL4 (Th2 cells), IFN-Y (Th1 cells) and IL-17 (Th17 cells)], it is now unclear whether the correlation between IL-9 levels and Th2 cell numbers is due to the direct production of this cytokine by Th2 cells or whether Th2-cell derived IL-4 supports the development of Th9 cells from either naive $\mathrm{CD}^{+} \mathrm{T}$ cells or terminal Th2 cells. Currently, only one group has reported low but detectable co-expression of IL-4 and IL9 during in vitro differentiation of Th2 cells (Chang et al., 2010). Surprisingly, to date there have been no reports addressing whether these cytokines are co-expressed by effector $\mathrm{CD}^{+}{ }^{+} \mathrm{T}$ cell populations that differentiate in vivo during a Th2-type immune response.

Th9 cells are a recently described subset of helper T cells that express IL-9 but not other helper T cell lineage-specific cytokines or transcription factors (Dardalhon et al., 2008; Veldhoen et al., 2008). The most definitive work that supports the existence and functional relevance of Th9 cells in vivo has come from the study of mice with a T cell-specific deletion of the transcription factor PU.1. These mice do not develop IL-9dependent allergic inflammation in the lungs and have only low levels of IL-9 in bronchoalveolar lavage fluid, but still 
develop normal numbers of Th2 cells. This finding indicates that, at least in this setting, Th9 cells are the main Tcell subset expressing IL-9 and that PU.1 is crucial for their development (Chang et al., 2010). Another transcription factor that is associated with Th9 cell development both in vitro and in vivo is interferon-regulatory factor 4 (IRF4) (Staudt et al., 2010), which also regulates Th2 and Th17 cell differentiation (Rengarajan et al., 2002; Brüstle et al., 2007). Characterization of Th9 cells in vitro showed that their generation is dependent on TGF- $\beta$ and IL-4 (Schmitt et al., 1994). The addition of IL-25 along with these two cytokines can further enhance IL-9 production by T cells in vitro. Th9 cells from IL25-deficient mice have decreased IL-9 expression and reduced airway inflammation in a model of asthma (Angkasekwinai et al., 2010), which shed light on the inflammatory function of this traditional regulatory cytokine. There have also been conflicting reports that various cytokines, such as IL-1 $\beta$, IL-6, IL-10, IL-12, IL-21, IFN- $\alpha$ and IFN- $\beta$, may have an additive effect on promoting Th9 cell generation in the presence of TGF- $\beta$ and IL-4 in vitro (Moreau et al., 2000). In addition, culturing human memory $T$ cells in the presence of TGF- $\beta$ (alone or in combination with IL-1 $\beta$, IL-4, IL-6, IL-12, IL21 or IL-23) was shown to promote IL-9 production with or without co-expression of IFN- $\gamma$ and IL-17 (Beriou et al., 2010).

\section{Th2 AND Tfh: Th2 WITH SPECIFIC MISSION}

$\mathrm{CD}^{+} \mathrm{T}$ follicular helper (Tfh) cells were first described in 2000, when several groups reported that a large proportion of $\mathrm{CD}^{+} \mathrm{T}$ cells in tonsils have a unique phenotype, expressing high levels of CXCR5 (Breitfeld et al., 2000; Schaerli et al., 2000). Tonsils are a secondary lymphoid organ similar to lymph nodes but with constant exposure to antigens via the throat and upper respiratory tract. Tonsils have, as a result, large and active germinal centers (GCs), which makes tonsils an appealing organ for the study of GCs. GCs are histologically distinct structures that develop within B cell zones (follicles) of secondary lymphoid tissues, and it is within GCs that the interrelated and multifaceted processes of B cell affinity maturation (hypermutation and selection), class switch recombination (CSR), plasma cell differentiation, and memory $B$ cell differentiation predominantly occur. These features make the GC key to protective immunity against many pathogens. GC formation depends on $\mathrm{CD}^{+}{ }^{+} \mathrm{T}$ cells, and many tonsillar $\mathrm{CD}^{+}{ }^{+} \mathrm{T}$ cells are located inside GCs (MacLennan, 1994; Allen et al., 2007). The chemokine receptor CXCR5 expressed by $B$ cells is required for migration by responding to $\mathrm{CXCL} 13$ (formerly B lymphocyte chemoattractant, or BLC) to form GCs (Förster et al., 1996). $\mathrm{CD}^{+} \mathrm{T}$ cells that express CXCR5 can also migrate in response to CXCL13 (Ansel et al., 1999) and relocate to follicles. This colocalization of $C D 4^{+} T$ cells with $B$ cells is critical for T-B interactions, as $T$ cell receptor-major histocompatibility complex class II (TCR-MHC II) engagement is pivotal to the restriction of cognate $B$ cell help. CD40L and other important surface molecules are crucial components of $T$ cell help to $B$ cells and require direct cell-cell contact. Recently, the identification of Bcl6 as a master regulator of Tfh differentiation (Johnston et al., 2009; Nurieva et al., 2009; Yu et al., 2009), the demonstration of the requirement of Tfh cells for $B$ cell help in vivo (Nurieva et al., 2008; Yu et al., 2009), and the identification of the importance of IL-21 for Tfh function (Nurieva et al., 2008; Linterman et al., 2010; Zotos et al., 2010) have now established Tfh cells as a distinct $\mathrm{CD}^{+} \mathrm{T}$ cell type, and one of great importance for protective immunity.

Although the differentiation has been fully discussed in these years, the function of Tfh remains elusive. The relationship of $\mathrm{CD} 4^{+} \mathrm{T}$ cell subsets, IL-4 production, and $\mathrm{B}$ cell help has long been a conundrum. IL-4 was recognized early as a B cell survival and differentiation factor (Paul and Ohara, 1987). The subsequent identification of Th1 and Th2 differentiation programs, with IL-4 as the canonical Th2 cytokine (Zhu et al., 2010), led to a widespread association of Th2 cells with B cell help. However, GC B cell numbers and serum IgG responses were mostly unaffected in mice with genetic defects blocking Th2 differentiation, beyond alterations in Ig isotypes (Kopf et al., 1995). It has now been determined that $B$ cell help requires Tfh cells, not Th2 cells in vivo (Johnston et al., 2009; Nurieva et al., 2009). Nevertheless, Tfh and GC Tfh cells have often reported to produce $\mathrm{IL}-4$, which was once been argued as IL4R $\mathrm{R}^{+}$cell, but finally confirmed by GFP and human CD2 knock-in reporter mouse experiments (Fazilleau et al., 2009; Reinhardt et al., 2009; Zaretsky et al., 2009). It has recently been determined that in some disease models, GC Tfh cells specifically produce IL-4 (Reinhardt et al., 2009; Yusuf et al., 2010), and this production depends on SAP and SLAM and can be independent of Th2 differentiation (Yusuf et al., 2010). Production of IL-4 by GC Th cells is required for optimal B cell help (King and Mohrs, 2009). IL-4 has antiapoptotic activity on B cells (Liu et al., 1989; Nelms et al., 1999; Wurster et al., 2002), which may be particularly crucial in GCs, as GC B cells are extremely susceptible to apoptosis (Liu et al., 1989).GC B cells express low levels of Bcl2 and high levels of Fas (Martinez-Valdez et al., 1996; Takahashi et al., 2001). IL-4 signaling in B cells prevents apoptosis by inducing the Bcl2 family member BclXL (Wurster et al., 2002). IL-4 signaling also potently increases glucose uptake and metabolism, enhancing cell survival and better poising GC B cells for additional proliferation (Dufort et al., 2007). While it has been challenging to identify a nonredundant requirement for GC Tfh cellproduced IL-4 in GCs for most experimental systems (Nurieva et al., 2009), IL-4 does contribute to sustaining GCs in some experimental models (King and Mohrs, 2009), which may be due to the cumulative effects of the antiapoptotic activity of IL-4 over many rounds of GC B cell proliferation. 


\section{NOTCH AND Th2}

In classic helper T cell differentiation mode, IL-12 and IL-4 induce Th1 and Th2 respectively, in vitro. However, not all Th1-cell responses require $\mathrm{IL}-12$ in vivo, and Th2-cell responses are remarkably independent of IL-4-receptor signaling, suggesting that other polarizing signals must exist. Accumulating evidence indicates that Notch is a candidate receptor that might mediate these signals. However, contrasting roles for Notch have been proposed: some evidence shows that Notch promotes Th1 cell differentiation, whereas other evidence supports a prominent role for Notch in Th2 cell differentiation. However, there is arguably more persuasive evidence that supports a role for Notch in Th2 cell differentiation. Expression of any of the four intracellular Notch proteins in CD4 ${ }^{+}$Tcells resulted in pronounced Th2 cell differentiation in several studies (Amsen et al., 2004; Amsen et al., 2007; Fang et al., 2007). Importantly, there is a lack of genetic evidence that supports the role of Notch in Th1 cell differentiation, whereas its role in Th2-cell differentiation is strongly supported by such studies (Amsen et al., 2007). Th2 cell responses to parasite antigens or to antigens adsorbed to aluminum hydroxide adjuvant were abrogated in vivo in the absence of RbPJ or in mice that expressed a dominantnegative form of the co-activator mAmL1. Although both $\mathrm{RbPJ}$ and $\mathrm{mAmL} 1$ have functions that are independent of Notch (Barolo et al., 2000), Th2 cell responses were also defective in the absence of both Notch1 and Notch2 (Amsen et al., 2007) (but not either one alone), formally confirming the requirement for Notch in these responses. However, although Notch was required for Th2 cell responses to parasite antigens, $T$ cells that were deficient for both Notch1 and Notch2, for RbPJ or for both presenilin 1 and presenilin 2 differentiated normally into Th2 cells in vitro in the presence of high amounts of exogenous IL-4. So, excess IL-4 can override the requirement of Notch ligation to generate Th2 cells in vitro. This discrepancy has been the root of some controversy regarding the requirement for Notch in Th2-cell differentiation (Ong et al., 2008).

\section{PROSPECT}

The model of $T$ cell subsets has been established for 25 years. It explains many immune phenomena and accelerates immunologic studies. In recent years, the classic Th1/Th2 paradigm has been modified. Induced Treg, Th17, Tfh, Th9, and Th22 have been considered as independent subsets early or late by most or some immunologists. On the other hand, some studies found a sort of IFN- $\mathrm{Y}^{+} \mathrm{IL}-17^{+}$in experimental autoimmune encephalomyelitis (EAE) disease model or in vitro cultured T cells (Lee et al., 2009; Wei et al., 2009). Treg cells are also reported to have plasticity (Yang et al., 2008). It seems that Th1/Th2 subsets are the most stable and have unique $\mathrm{T}$ cell fate, and only a few researchers declared the reprogramming of Th2, which required very long period of culturing (Hegazy et al., 2010). In future studies, new transcript factors may be identified to involve in IL-4 or IL-2 signaling in Th2, and gene locus modification could be interesting to study. With more and more disease models, new subsets which are not so classical may be found, but the stability and universality of these cells still need further consideration. With more understanding of Th2 differentiation and function, we can select drug targets for Th2-related diseases.

\section{ABBREVIATIONS}

APC, antigen presenting cell; CSR, class switch recombination; IL, interleukin; LN, lymph nodes; MBD2, methyl-CpG-binding domain protein 2; MHC-II complex, major histocompatibility complex class II; NURD, nucleosome remodeling and histone deacetylase; STAT4, signal transducer and activator of transcription 4; Th, helper T cell; Tfh, T follicular helper cells; TCR, T cell receptor; TGF- $\beta$, transforming growth factor- $\beta$; Treg, regulatory $\mathrm{T}$ cell

\section{REFERENCES}

Abbas, A.K., Murphy, K.M., and Sher, A. (1996). Functional diversity of helper T lymphocytes. Nature 383, 787-793.

Agarwal, S., Avni, O., and Rao, A. (2000). Cell-type-restricted binding of the transcription factor NFAT to a distal IL-4 enhancer in vivo. Immunity 12, 643-652.

Agarwal, S., and Rao, A. (1998). Modulation of chromatin structure regulates cytokine gene expression during $\mathrm{T}$ cell differentiation. Immunity 9, 765-775.

Allen, C.D., Okada, T., and Cyster, J.G. (2007). Germinal-center organization and cellular dynamics. Immunity 27, 190-202.

Amsen, D., Antov, A., Jankovic, D., Sher, A., Radtke, F., Souabni, A., Busslinger, M., McCright, B., Gridley, T., and Flavell, R.A. (2007). Direct regulation of Gata3 expression determines the $T$ helper differentiation potential of Notch. Immunity 27, 89-99.

Amsen, D., Blander, J.M., Lee, G.R., Tanigaki, K., Honjo, T., and Flavell, R.A. (2004). Instruction of distinct CD4 T helper cell fates by different notch ligands on antigen-presenting cells. Cell 117, 515-526.

Angkasekwinai, P., Chang, S.H., Thapa, M., Watarai, H., and Dong, C. (2010). Regulation of IL-9 expression by IL-25 signaling. Nat Immunol 11, 250-256.

Ansel, K.M., McHeyzer-Williams, L.J., Ngo, V.N., McHeyzer-Williams, M.G., and Cyster, J.G. (1999). In vivo-activated CD4 T cells upregulate CXC chemokine receptor 5 and reprogram their response to lymphoid chemokines. J Exp Med 190, 1123-1134.

Barolo, S., Walker, R.G., Polyanovsky, A.D., Freschi, G., Keil, T., and Posakony, J.W. (2000). A notch-independent activity of suppressor of hairless is required for normal mechanoreceptor physiology. Cell 103, 957-969.

Beriou, G., Bradshaw, E.M., Lozano, E., Costantino, C.M., Hastings, W.D., Orban, T., Elyaman, W., Khoury, S.J., Kuchroo, V.K., Baecher-Allan, C., et al. (2010). TGF-beta induces IL-9 production from human Th17 cells. J Immunol 185, 46-54.

Bird, J.J., Brown, D.R., Mullen, A.C., Moskowitz, N.H., Mahowald, M. 
A., Sider, J.R., Gajewski, T.F., Wang, C.R., and Reiner, S.L. (1998). Helper $T$ cell differentiation is controlled by the cell cycle. Immunity 9, 229-237.

Breitfeld, D., Ohl, L., Kremmer, E., Ellwart, J., Sallusto, F., Lipp, M., and Förster, R. (2000). Follicular B helper T cells express CXC chemokine receptor 5 , localize to $B$ cell follicles, and support immunoglobulin production. J Exp Med 192, 1545-1552.

Brinkmann, V., Davis, M.D., Heise, C.E., Albert, R., Cottens, S., Hof, R., Bruns, C., Prieschl, E., Baumruker, T., Hiestand, P., et al. (2002). The immune modulator FTY720 targets sphingosine 1phosphate receptors. J Biol Chem 277, 21453-21457.

Brusselle, G.G., Kips, J.C., Tavernier, J.H., van der Heyden, J.G., Cuvelier, C.A., Pauwels, R.A., and Bluethmann, H. (1994). Attenuation of allergic airway inflammation in IL-4 deficient mice. Clin Exp Allergy 24, 73-80.

Brüstle, A., Heink, S., Huber, M., Rosenplänter, C., Stadelmann, C., Yu, P., Arpaia, E., Mak, T.W., Kamradt, T., and Lohoff, M. (2007). The development of inflammatory $\mathrm{T}(\mathrm{H})-17$ cells requires interferonregulatory factor 4. Nat Immunol 8, 958-966.

Busse, W.W., and Lemanske, R.F. Jr. (2001). Asthma. N Engl J Med 344, 350-362.

Chang, H.C., Sehra, S., Goswami, R., Yao, W., Yu, Q., Stritesky, G.L., Jabeen, R., McKinley, C., Ahyi, A.N., Han, L., et al. (2010). The transcription factor PU.1 is required for the development of IL-9producing $\mathrm{T}$ cells and allergic inflammation. Nat Immunol 11, 527-534.

Cohn, L., Tepper, J.S., and Bottomly, K. (1998). IL-4-independent induction of airway hyperresponsiveness by Th2, but not Th1, cells. J Immunol 161, 3813-3816.

Corry, D.B., Folkesson, H.G., Warnock, M.L., Erle, D.J., Matthay, M. A., Wiener-Kronish, J.P., and Locksley, R.M. (1996). Interleukin 4, but not interleukin 5 or eosinophils, is required in a murine model of acute airway hyperreactivity. J Exp Med 183, 109-117.

Yusuf, I., Kageyama, R., Monticelli, L., Johnston, R.J., Ditoro, D., Hansen, K., Barnett, B., and Crotty, S. (2010). Germinal center T follicular helper cell IL-4 production is dependent on signaling lymphocytic activation molecule receptor (CD150). J Immunol 185, 190-202.

Dardalhon, V., Awasthi, A., Kwon, H., Galileos, G., Gao, W., Sobel, R. A., Mitsdoerffer, M., Strom, T.B., Elyaman, W., Ho, I.C., et al. (2008). IL-4 inhibits TGF-beta-induced Foxp3+ T cells and, together with TGF-beta, generates IL-9+ IL-10+ Foxp3(-) effector T cells. Nat Immunol 9, 1347-1355.

Dufort, F.J., Bleiman, B.F., Gumina, M.R., Blair, D., Wagner, D.J., Roberts, M.F., Abu-Amer, Y., and Chiles, T.C. (2007). Cutting edge: IL-4-mediated protection of primary $B$ lymphocytes from apoptosis via Stat6-dependent regulation of glycolytic metabolism. J Immunol 179, 4953-4957.

Fang, T.C., Yashiro-Ohtani, Y., Del Bianco, C., Knoblock, D.M., Blacklow, S.C., and Pear, W.S. (2007). Notch directly regulates Gata3 expression during $T$ helper 2 cell differentiation. Immunity 27, 100-110.

Fazilleau, N., McHeyzer-Williams, L.J., Rosen, H., and McHeyzerWilliams, M.G. (2009). The function of follicular helper T cells is regulated by the strength of $\mathrm{T}$ cell antigen receptor binding. Nat Immunol 10, 375-384.

Förster, R., Mattis, A.E., Kremmer, E., Wolf, E., Brem, G., and Lipp, M. (1996). A putative chemokine receptor, BLR1, directs B cell migration to defined lymphoid organs and specific anatomic compartments of the spleen. Cell 87, 1037-1047.

Gessner, A., Blum, H., and Röllinghoff, M. (1993). Differential regulation of IL-9-expression after infection with Leishmania major in susceptible and resistant mice. Immunobiology 189 , 419-435.

Harris, N.L., Watt, V., Ronchese, F., and Le Gros, G. (2002). Differential $\mathrm{T}$ cell function and fate in lymph node and nonlymphoid tissues. J Exp Med 195, 317-326.

Hegazy, A.N., Peine, M., Helmstetter, C., Panse, I., Fröhlich, A., Bergthaler, A., Flatz, L., Pinschewer, D.D., Radbruch, A., and Löhning, M. (2010). Interferons direct Th2 cell reprogramming to generate a stable GATA-3(+)T-bet(+) cell subset with combined Th2 and Th1 cell functions. Immunity 32, 116-128.

Herrick, C.A., and Bottomly, K. (2003). To respond or not to respond: T cells in allergic asthma. Nat Rev Immunol 3, 405-412.

Ho, I.C., and Glimcher, L.H. (2002). Transcription: tantalizing times for T cells. Cell 109, S109-S120.

Ho, I.C., Hodge, M.R., Rooney, J.W., and Glimcher, L.H. (1996). The proto-oncogene c-maf is responsible for tissue-specific expression of interleukin-4. Cell 85, 973-983.

Hutchins, A.S., Mullen, A.C., Lee, H.W., Sykes, K.J., High, F.A., Hendrich, B.D., Bird, A.P., and Reiner, S.L. (2002). Gene silencing quantitatively controls the function of a developmental transactivator. Mol Cell 10, 81-91.

Johnston, R.J., Poholek, A.C., DiToro, D., Yusuf, I., Eto, D., Barnett, B., Dent, A.L., Craft, J., and Crotty, S. (2009). Bcl6 and Blimp-1 are reciprocal and antagonistic regulators of $T$ follicular helper cell differentiation. Science 325, 1006-1010.

Kaplan, M.H., Schindler, U., Smiley, S.T., and Grusby, M.J. (1996). Stat6 is required for mediating responses to $\mathrm{IL}-4$ and for development of Th2 cells. Immunity 4, 313-319.

Kim, J., Woods, A., Becker-Dunn, E., and Bottomly, K. (1985). Distinct functional phenotypes of cloned la-restricted helper T cells. J Exp Med 162, 188-201.

King, I.L., and Mohrs, M. (2009). IL-4-producing CD4+ T cells in reactive lymph nodes during helminth infection are $T$ follicular helper cells. J Exp Med 206, 1001-1007.

Kips, J.C., Brusselle, G.G., Joos, G.F., Peleman, R.A., Devos, R.R., Tavernier, J.H., and Pauwels, R.A. (1995). Importance of interleukin-4 and interleukin-12 in allergen-induced airway changes in mice. Int Arch Allergy Immunol 107, 115-118.

Kopf, M., Le Gros, G., Coyle, A.J., Kosco-Vilbois, M., and Brombacher, F. (1995). Immune responses of IL-4, IL-5, IL-6 deficient mice. Immunol Rev 148, 45-69.

Lee, G.R., Fields, P.E., and Flavell, R.A. (2001). Regulation of IL-4 gene expression by distal regulatory elements and GATA-3 at the chromatin level. Immunity 14, 447-459.

Lee, Y.K., Turner, H., Maynard, C.L., Oliver, J.R., Chen, D., Elson, C. O., and Weaver, C.T. (2009). Late developmental plasticity in the T helper 17 lineage. Immunity 30, 92-107.

Li, Z., Zhang, Y., Liu, Z., Wu, X., Zheng, Y., Tao, Z., Mao, K., Wang, J., Lin, G., Tian, L., et al. (2011). ECM1 controls T(H)2 cell egress from lymph nodes through re-expression of S1P(1). Nat Immunol 12, 178-185

Linterman, M.A., Beaton, L., Yu, D., Ramiscal, R.R., Srivastava, M., Hogan, J.J., Verma, N.K., Smyth, M.J., Rigby, R.J., and Vinuesa, C.G. (2010). IL-21 acts directly on B cells to regulate Bcl-6 
expression and germinal center responses. J Exp Med 207, 353-363.

Liu, Y.J., Joshua, D.E., Williams, G.T., Smith, C.A., Gordon, J., and MacLennan, I.C. (1989). Mechanism of antigen-driven selection in germinal centres. Nature 342, 929-931.

Liu, Z., Li, Z., Mao, K., Zou, J., Wang, Y., Tao, Z., Lin, G., Tian, L., Ji, Y., Wu, X., et al. (2009). Dec2 promotes Th2 cell differentiation by enhancing IL-2R signaling. J Immunol 183, 6320-6329.

Lommatzsch, M., Julius, P., Kuepper, M., Garn, H., Bratke, K., Irmscher, S., Luttmann, W., Renz, H., Braun, A., and Virchow, J.C. (2006). The course of allergen-induced leukocyte infiltration in human and experimental asthma. J Allergy Clin Immunol 118, 91-97.

MacLennan, I.C. (1994). Germinal centers. Annu Rev Immunol 12, 117-139.

Mandala, S., Hajdu, R., Bergstrom, J., Quackenbush, E., Xie, J., Milligan, J., Thornton, R., Shei, G.J., Card, D., Keohane, C., et al. (2002). Alteration of lymphocyte trafficking by sphingosine-1phosphate receptor agonists. Science 296, 346-349.

Martinez-Valdez, H., Guret, C., de Bouteiller, O., Fugier, I., Banchereau, J., and Liu, Y.J. (1996). Human germinal center B cells express the apoptosis-inducing genes Fas, c-myc, P53, and Bax but not the survival gene bcl-2. J Exp Med 183, 971-977.

Medoff, B.D., Thomas, S.Y., and Luster, A.D. (2008). T cell trafficking in allergic asthma: the ins and outs. Annu Rev Immunol 26, 205-232.

Mohrs, M., Blankespoor, C.M., Wang, Z.E., Loots, G.G., Afzal, V., Hadeiba, H., Shinkai, K., Rubin, E.M., and Locksley, R.M. (2001). Deletion of a coordinate regulator of type 2 cytokine expression in mice. Nat Immunol 2, 842-847.

Moreau, J.F., Dechanet-Merville, J., and Taupin, J.L. (2000). T cells and cellular immunity; T receptors (structure, diversity, repertory); differentiation antigens (CD4, CD8); activation; auxillary T cells and immunoregulation; lymphokines (interferons, TNF, IL-1, IL-2, IL-4) and cytotoxicity; concept of cellular immunity deficit. Rev Prat 50, 2183-2193.

Mosmann, T.R., Cherwinski, H., Bond, M.W., Giedlin, M.A., and Coffman, R.L. (1986). Two types of murine helper T cell clone. I. Definition according to profiles of lymphokine activities and secreted proteins. J Immunol 136, 2348-2357.

Mullen, A.C., High, F.A., Hutchins, A.S., Lee, H.W., Villarino, A.V., Livingston, D.M., Kung, A.L., Cereb, N., Yao, T.P., Yang, S.Y., et al. (2001). Role of T-bet in commitment of TH1 cells before IL-12dependent selection. Science 292, 1907-1910.

Murphy, K.M., and Reiner, S.L. (2002). The lineage decisions of helper T cells. Nat Rev Immunol 2, 933-944.

Nelms, K., Keegan, A.D., Zamorano, J., Ryan, J.J., and Paul, W.E. (1999). The IL-4 receptor: signaling mechanisms and biologic functions. Annu Rev Immunol 17, 701-738.

Nurieva, R.I., Chung, Y., Hwang, D., Yang, X.O., Kang, H.S., Ma, L., Wang, Y.H., Watowich, S.S., Jetten, A.M., Tian, Q., et al. (2008). Generation of $\mathrm{T}$ follicular helper cells is mediated by interleukin-21 but independent of T helper 1, 2, or 17 cell lineages. Immunity 29, 138-149.

Nurieva, R.I., Chung, Y., Martinez, G.J., Yang, X.O., Tanaka, S., Matskevitch, T.D., Wang, Y.H., and Dong, C. (2009). Bcl6 mediates the development of $\mathrm{T}$ follicular helper cells. Science 325 , 1001-1005.
O'Shea, J.J., Lahesmaa, R., Vahedi, G., Laurence, A., and Kanno, Y. (2011). Genomic views of STAT function in CD4+ T helper cell differentiation. Nat Rev Immunol 11, 239-250.

Ong, C.T., Sedy, J.R., Murphy, K.M., and Kopan, R. (2008). Notch and presenilin regulate cellular expansion and cytokine secretion but cannot instruct Th1/Th2 fate acquisition. PLoS One 3, e2823.

Ouyang, W., Löhning, M., Gao, Z., Assenmacher, M., Ranganath, S., Radbruch, A., and Murphy, K.M. (2000). Stat6-independent GATA3 autoactivation directs IL-4-independent Th2 development and commitment. Immunity 12, 27-37.

Paul, W.E., and Ohara, J. (1987). B-cell stimulatory factor-1/ interleukin 4. Annu Rev Immunol 5, 429-459.

Reinhardt, R.L., Liang, H.E., and Locksley, R.M. (2009). Cytokinesecreting follicular $\mathrm{T}$ cells shape the antibody repertoire. Nat Immunol 10, 385-393.

Rengarajan, J., Mowen, K.A., McBride, K.D., Smith, E.D., Singh, H., and Glimcher, L.H. (2002). Interferon regulatory factor 4 (IRF4) interacts with NFATc2 to modulate interleukin 4 gene expression. J Exp Med 195, 1003-1012.

Rivera, J., Proia, R.L., and Olivera, A. (2008). The alliance of sphingosine-1-phosphate and its receptors in immunity. Nat Rev Immunol 8, 753-763.

Robinson, D., Hamid, Q., Bentley, A., Ying, S., Kay, A.B., and Durham, S.R. (1993). Activation of CD4+ T cells, increased TH2type cytokine mRNA expression, and eosinophil recruitment in bronchoalveolar lavage after allergen inhalation challenge in patients with atopic asthma. J Allergy Clin Immunol 92, 313-324.

Robinson, D.S., Hamid, Q., Ying, S., Tsicopoulos, A., Barkans, J., Bentley, A.M., Corrigan, C., Durham, S.R., and Kay, A.B. (1992). Predominant TH2-like bronchoalveolar T-lymphocyte population in atopic asthma. N Engl J Med 326, 298-304.

Rothoeft, T., Gonschorek, A., Bartz, H., Anhenn, O., and Schauer, U. (2003). Antigen dose, type of antigen-presenting cell and time of differentiation contribute to the T helper $1 / T$ helper 2 polarization of naive T cells. Immunology 110, 430-439.

Schaerli, P., Willimann, K., Lang, A.B., Lipp, M., Loetscher, P., and Moser, B. (2000). CXC chemokine receptor 5 expression defines follicular homing T cells with B cell helper function. J Exp Med 192, 1553-1562.

Schmitt, E., Germann, T., Goedert, S., Hoehn, P., Huels, C., Koelsch, S., Kühn, R., Müller, W., Palm, N., and Rüde, E. (1994). IL-9 production of naive CD4+ T cells depends on IL-2, is synergistically enhanced by a combination of TGF-beta and IL-4, and is inhibited by IFN-gamma. J Immunol 153, 3989-3996.

Schwab, S.R., and Cyster, J.G. (2007). Finding a way out: lymphocyte egress from lymphoid organs. Nat Immunol 8, 1295-1301.

Schweitzer, A.N., Borriello, F., Wong, R.C., Abbas, A.K., and Sharpe, A.H. (1997). Role of costimulators in T cell differentiation: studies using antigen-presenting cells lacking expression of CD80 or CD86. J Immunol 158, 2713-2722.

Staudt, V., Bothur, E., Klein, M., Lingnau, K., Reuter, S., Grebe, N., Gerlitzki, B., Hoffmann, M., Ulges, A., Taube, C., et al. (2010). Interferon-regulatory factor 4 is essential for the developmental program of T helper 9 cells. Immunity 33, 192-202.

Szabo, S.J., Kim, S.T., Costa, G.L., Zhang, X., Fathman, C.G., and Glimcher, L.H. (2000). A novel transcription factor, T-bet, directs Th1 lineage commitment. Cell 100, 655-669. 
Szabo, S.J., Sullivan, B.M., Stemmann, C., Satoskar, A.R., Sleckman, B.P., and Glimcher, L.H. (2002). Distinct effects of T-bet in TH1 lineage commitment and IFN-gamma production in CD4 and CD8 T cells. Science 295, 338-342.

Takahashi, Y., Ohta, H., and Takemori, T. (2001). Fas is required for clonal selection in germinal centers and the subsequent establishment of the memory B cell repertoire. Immunity 14, 181-192.

Tanaka, S., Motomura, Y., Suzuki, Y., Yagi, R., Inoue, H., Miyatake, S., and Kubo, M. (2011). The enhancer HS2 critically regulates GATA3-mediated II4 transcription in $\mathrm{T}(\mathrm{H}) 2$ cells. Nat Immunol 12, 77-85.

Thomas, S.Y., Banerji, A., Medoff, B.D., Lilly, C.M., and Luster, A.D. (2007). Multiple chemokine receptors, including CCR6 and CXCR3, regulate antigen-induced $\mathrm{T}$ cell homing to the human asthmatic airway. J Immunol 179, 1901-1912.

Veldhoen, M., Uyttenhove, C., van Snick, J., Helmby, H., Westendorf, A., Buer, J., Martin, B., Wilhelm, C., and Stockinger, B. (2008). Transforming growth factor-beta 'reprograms' the differentiation of T helper 2 cells and promotes an interleukin 9-producing subset. Nat Immunol 9, 1341-1346.

Walker, C., Bode, E., Boer, L., Hansel, T.T., Blaser, K., and Virchow, J. C. Jr. (1992). Allergic and nonallergic asthmatics have distinct patterns of T-cell activation and cytokine production in peripheral blood and bronchoalveolar lavage. Am Rev Respir Dis 146, 109-115.

Weaver, C.T., and Hatton, R.D. (2009). Interplay between the TH17 and TReg cell lineages: a (co-)evolutionary perspective. Nat Rev Immunol 9, 883-889.

Wei, G., Wei, L., Zhu, J., Zang, C., Hu-Li, J., Yao, Z., Cui, K., Kanno, Y., Roh, T.Y., Watford, W.T., et al. (2009). Global mapping of
H3K4me3 and H3K27me3 reveals specificity and plasticity in lineage fate determination of differentiating CD4+ T cells. Immunity 30, 155-167.

Wurster, A.L., Rodgers, V.L., White, M.F., Rothstein, T.L., and Grusby, M.J. (2002). Interleukin-4-mediated protection of primary B cells from apoptosis through Stat6-dependent up-regulation of $\mathrm{Bcl}-\mathrm{xL}$. J Biol Chem 277, 27169-27175.

Yang, X.O., Angkasekwinai, P., Zhu, J., Peng, J., Liu, Z., Nurieva, R., Liu, X., Chung, Y., Chang, S.H., Sun, B., et al. (2009). Requirement for the basic helix-loop-helix transcription factor Dec2 in initial TH2 lineage commitment. Nat Immunol 10, 1260-1266.

Yang, X.O., Nurieva, R., Martinez, G.J., Kang, H.S., Chung, Y., Pappu, B.P., Shah, B., Chang, S.H., Schluns, K.S., Watowich, S. S., et al. (2008). Molecular antagonism and plasticity of regulatory and inflammatory T cell programs. Immunity 29, 44-56.

Yu, D., Rao, S., Tsai, L.M., Lee, S.K., He, Y., Sutcliffe, E.L., Srivastava, M., Linterman, M., Zheng, L., Simpson, N., et al. (2009). The transcriptional repressor Bcl-6 directs $\mathrm{T}$ follicular helper cell lineage commitment. Immunity 31, 457-468.

Zaretsky, A.G., Taylor, J.J., King, I.L., Marshall, F.A., Mohrs, M., and Pearce, E.J. (2009). T follicular helper cells differentiate from Th2 cells in response to helminth antigens. J Exp Med 206, 991-999.

Zhu, J., Yamane, H., and Paul, W.E. (2010). Differentiation of effector CD4 T cell populations ( ${ }^{*}$ ). Annu Rev Immunol 28, 445-489.

Zotos, D., Coquet, J.M., Zhang, Y., Light, A., D’Costa, K., Kallies, A., Corcoran, L.M., Godfrey, D.I., Toellner, K.M., Smyth, M.J., et al. (2010). IL-21 regulates germinal center B cell differentiation and proliferation through a B cell-intrinsic mechanism. J Exp Med 207, 365-378. 